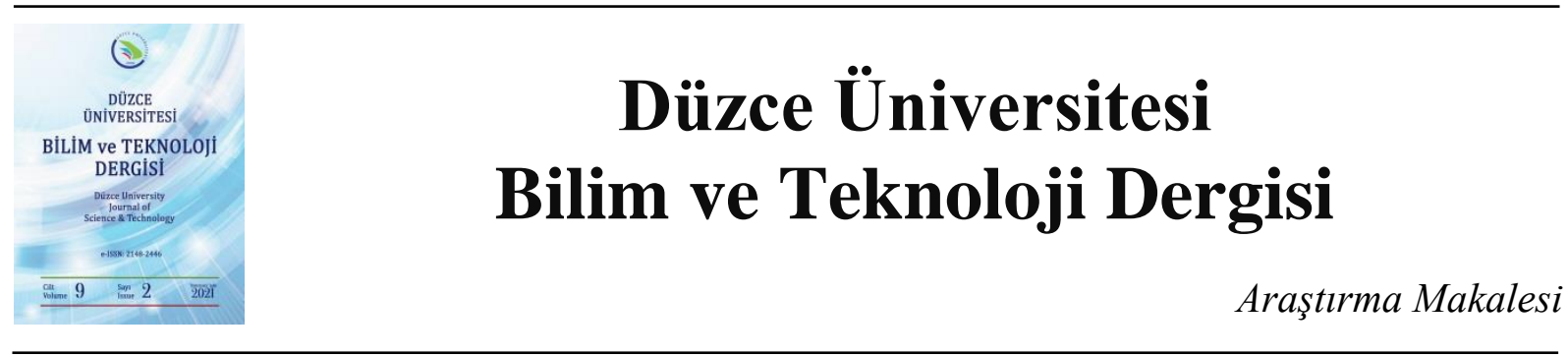

\section{Benzetilmiş Tavlama Algoritması ile Fazör Ölçüm Birimlerinin Optimal Yerleşimi}

\author{
Emre ŞIK ${ }^{\mathrm{a}, *}$, (D) Salih TOSUN ${ }^{\mathrm{b}}$ \\ ${ }^{a}$ Elektrik-Elektronik ve Bilgisayar Mühendisliği Bölümü, Fen Bilimleri Enstitüsü, Düzce Üniversitesi, Düzce, \\ TÜRKIYE \\ ${ }^{b}$ Elektrik-Elektronik Mühendisliği Bölümü, Teknoloji Fakültesi, Düzce Üniversitesi, Düzce, TÜRKIYE \\ * Sorumlu yazarın e-posta adresi: emresk.3817@gmail.com.tr
}

DOI: 10.29130dubited.847805

ÖZET

Gelişen teknoloji ve artan nüfus ile birlikte elektrik enerjisine olan ihtiyaç ve talep her geçen gün artmaktadır. Enerji talebindeki artış güç sistemlerini kararlılık sınırlarına yakın bölgelerde çalışmaya zorlamaktadır. $\mathrm{Bu}$ durum güç sistemlerinde gerilim kararsızlı̆̆ ve gerilim çökmesi gibi sonuçlar doğurmaktadır. Güç sistemlerinin kararlılık durumunun gerçek zamanlı olarak takip edilmesi kritik önem taşımaktadır. Bu sebeple güç sistemlerinin izlenebilirliği ve kontrolünü sağlayan sistemlere duyulan ihtiyaç da artmıştır. Fazör Ölçüm Birimi (FÖB) bu sistemlerden birisidir. FÖB'ler Global Positioning System (GPS) yardımılla gerilim, akım ve faz açısının anlık olarak takip edilmesine imkan sağlamaktadır. Ancak maliyet kısıtı nedeniyle FÖB'ler iletim hatlarında tüm baralara yerleştirilememektedirler. Bu yüzden FÖB'leri şebekeye maksimum gözlenebilirliği sağlayacak optimal bir şekilde yerleştirmek önem arz etmektedir. Optimal yerleşim için literatürde pek çok yöntem kullanılmaktadır. Bu çalışmada Benzetilmiş Tavlama Algoritması kullanılarak Enterkonnekte güç sisteminin bir kısmı olan Trakya Güç Sistemi'ne optimal FÖB yerleşimi yapılmıştır. Benzetilmiş Tavlama Algoritması ile elde edilen sonuçlar, Power System Analysis Toolbox (PSAT) programı ile FÖB yerleşim algoritmalarından çıkan sonuçlarla karşılaştırılmıştır. Bu çalışma ile sistemin tamamını anlık olarak takip edebilmek için kullanılan FÖB'lerin, Trakya Güç Sistemi'nde hangi baralara yerleştirilmesi gerektiği tespit edilmiş ve optimal yerleşim gerçekleştirilmiştir.

Anahtar Kelimeler: Güç Sistemi, Fazör Ölçüm Birimi, Optimal FÖB Yerleşimi, Benzetilmiş Tavlama Algoritmast.

\section{Optimal Placement of Phasor Measurement Units with Simulated Annealing Algorithm}

\begin{abstract}
With the developing technology and increasing population, the need and demand for electrical energy is increasing day by day. The increase in energy demand, forces power systems to operate in regions close to stability limits. This situation gives results such as voltage instability and voltage collapse in power system. It is critical to monitor the stability of power systems in real time. For this reason, the need for systems that provide traceability and control of power systems has increased. Phasor Measurement Unit (PMU) is one of these systems. The PMUs provides to instantly monitor voltage, current and phase angle with the help of Global Positioning System (GPS). However, due to cost constraints, PMUs cannot be placed in all busbars in transmission lines. Therefore, it is important to place the PMUs in the grid in an optimal way to ensure maximum observability. Many methods are used in the literature for optimal placement. In this study, the optimal PMU placement was made on the Trakya Power System by using the Simulated Annealing Algorithm. The obtained results have been compared with the results obtained from the PMU placement algorithms in the Power System Analysis Toolbox (PSAT) program. With this study, the PMUs which are used to monitor the entire system momentarily, have been optimally placed in the Trakya Power System.
\end{abstract}

Geliş: 28/12/2020, Düzeltme: 14/04/2021, Kabul: 20/04/2020 


\section{GIRIS}

Elektrik enerjisi günümüzde her alanda ve her anda kullanılan vazgeçilmez ihtiyaçlardan birisidir. Tüketiciye kesintisiz bir şekilde elektrik enerjisi aktarmak için yeni şebekeler devreye alınmakta ve alternatif enerji kaynakları aranmaktadır. Mevcut şebekeler de ihtiyacı karşılayabilmek için kararlılık sınırlarına yakın bölgelerde çalışmaktadırlar. Bu sebeple güç sistemlerinin anlık olarak takip edilmesi gerekmektedir.

Elektrik kontrol merkezleri güç sistemlerini izlemek için durum kestirimini kullanır. Durum kestirimi farklı trafo merkezlerinden alınan ölçümleri kullanarak güç sisteminin durumunu ortaya koyar [1]. Geniş alan ölçümleri uzun yıllardır güç sistemi operasyonlarının ayrılmaz bir parçası olmuştur. Uzak bağlantı hatları ve generatör çıkış güçleri üzerindeki güç akışlarını, gerçek zamanlı sağlayarak kontrol sistemlerinde kullanılmışlardır [2]. Yakın zamana kadar bu ölçümler trafo merkezlerinde kurulu olan uzak terminal birimlerinden (RTU) gerçek zamanlı ölçümleri toplayan denetleyici kontrol ve veri toplama (SCADA) sistemi aracılığıyla elde edilmekteydi [3]. Günümüzde gelişen teknoloji ile birlikte Fazör Ölçüm Birimi (FÖB) gibi daha yeni sistemler kullanılmaya başlanmıştır.

Senkronize fazör ölçümleri (SPM), güç sistemini çalıştırmak, korumak ve kontrol etmek için verimli bir araç olarak tanımlanmaktadır. FÖB, küresel konumlandırma sistemi (GPS) ile senkronize edilmiş bir şekilde bağlandıkları baranın voltaj ve akım fazörlerinin senkronize ölçümlerini sağlamak ve geniş alan izleme sistemlerine uygulanmaları için 1990'larda tanıtılmıştır. FÖB'lerin ortaya çıkışı ölçümleri birkaç milisaniyede almayı mümkün kılmıştır. FÖB ölçümlerine dayalı bir durum tahmini, sistemin durumlarını saniyeden kısa bir sürede güncelleyebilmektedir. FÖB ölçümleri geleneksel SCADA ölçümlerinden daha doğru sonuç sağlamaktadır. FÖB'lerin ölçüm raporlama hızı $50 \mathrm{~Hz}$ sistemler için saniyede 50,60 Hz sistemler için ise saniyede 60 defadır. Bu da SCADA ölçümlerinin raporlama hızından çok daha yüksektir [4-6].

Günümüzde FÖB teknolojisinden tam olarak yararlanılmış olmasa da kullanıldığı sistemler ve prototiplerde oldukça iyi sonuçlar verdiği ve güç sistemleri kontrolü için önemli bir bileşen olduğu görülmüştür [7].

Sistemin tam gözlenebilirliğini sağlayabilmek için teorik olarak güç sisteminin tüm baralarına FÖB yerleştirmek çözüm sağlayacaktır. Ancak FÖB'lerin yüksek maliyetleri nedeniyle güç sisteminin tamamına yerleştirilmesi maliyeti önemli ölçüde artırmaktadır. Bu sebeple FÖB'lerin sisteme optimal yerleştirilmesi gündeme gelmektedir. Literatürde kullanılan optimal FÖB yerleşim teknikleri FÖB sayısını en aza indirgemek için önerilmiştir [8-9].

Literatürde FÖB'lerin optimal yerleşimi için matematiksel ve sezgisel yöntemler başlığ çok yöntem mevcuttur. Bunları inceleyecek olursak, Sodhi vd. FÖB'lerin optimal yerleşimi için sayısal gözlenebilirlik analizi ve topolojik gözlenebilirliğe dayalı iki aşamalı bir yöntem önermişlerdir [10]. Chakrabarti vd. Tamsayı Karesel Programlama Tekniği önererek IEEE test sistemlerinde optimal FÖB yerleşimleri gerçekleştirmişlerdir [11]. Marin vd. Genetik Algoritma tabanlı bir prosedür geliştirmişlerdir. Bu yöntem ile minimum sayıda FÖB kullanılması için ölçülmesi gereken fazör sayıları ilişkilendirilmiştir [12]. Haijan vd. tam gözlenebilirlik için Parçacık Sürü Optimizasyonu'na yeni bir yaklaşım getirerek İkili Parçacık Sürü Optimizasyonu önermişler ve IEEE test sistemlerinde elde ettikleri sonuçları literatürdeki çalışmalarla karşılaştırmışlardır [13]. Al-Mohammed vd. ve Peng vd. Diferansiyel Evrim Algoritması'nı baz alarak optimal FÖB yerleştirmesini gerçekleştirmişlerdir [14-15]. Abdelsalam vd. güç kayıplarını azaltmak için 33 baradan oluşan bir dağıtım sistemini Karınca Kolonisi Optimizasyonu ile yeniden yapılandırarak, aynı sisteme Açgözlü Algoritması ile optimal 
FÖB yerleşimi gerçekleştirmişlerdir [16]. Mandava vd. Ağaç Arama Tekniği ve Yayılan Ağaç Yaklaşımı ile 14 ve 30 baralık sistemlerde FÖB'lerin optimal yerleşimini gerçekleştirmişlerdir [17]. Almunif vd. karma tamsayılı doğrusal programlama ve doğrusal olmayan programlama olarak iki matematiksel programlama formülasyonu önererek IEEE test sistemleri ve Polonya Güç Sistemi üzerinde optimal FÖB yerleşimi gerçekleştirmişlerdir [18]. Johnson vd. ise FÖB'lerin optimal yerleştirilme üzerine kapsamlı bir literatür incelemesi gerçekleştirmişlerdir [19].

Bu çalışmadada öncelikle kullanılan algoritma IEEE'nin 14 ve 30 baralı test sistemlerinde denenmiş, sonrasında 89 baradan oluşan Trakya İletim Sistemi'nde Benzetilmiş Tavlama Algoritması kullanılarak optimal FÖB yerleşimi yapılmıştır. Elde edilen sonuçlar PSAT'ta bulunan FÖB yerleşim algoritmalarından çıkan sonuçlarla karşılaştırılmıştır. Elde edilen sonuçlarla, sistemin tamamını gözlemleyebilmek için FÖB'lerin yerleştirilmesi gereken baralar belirlenmiştir.

\section{MATERYAL METOT}

\section{A. FAZÖR ÖLÇÜM BİRIMII YERLESTTIRME KURALLARI}

FÖB'ler güç sistemlerinin gerilim ve akım fazörlerini ölçerek gözlenebilirliğini sağlamak amacıyla şebekeye yerleştirilen cihazlardır. Elektrik güç sisteminde, düğüm voltajı doğrudan ölçülebiliyorsa veya diğer voltaj fazörü ve akım fazörü ile hesaplanabiliyorsa, düğüme gözlemlenebilir denir. Şebeke gözlenebilirlik analizi için Sayısal Yöntem ve Topolojik Yöntem olmak üzere iki metot vardır [20].

FÖB bağlı olduğu baranın akım ve voltaj fazörlerini ölçme yeteneğine sahip olduğundan, komşu baraların gerilim ve akım fazörleri, Ohm Kanunu ve Kirşof Akım Yasası yardımıyla elde edilebilir. Bu bir kural dizisi olarak siralanırsa;

- Kural 1: FÖB bağlı olan baranın gerilim fazörü ve tüm dal akımları bilinir.

- Kural 2: FÖB'ün yerleştirildiği baranın tüm komşu baralarının gerilimi Ohm Kanunu sayesinde hesaplanabilir.

- Kural 3: Bir dalın her iki ucundaki gerilim değeri biliniyorsa, dal akımı Ohm Kanunu kullanılarak hesaplanabilir.

- Kural 4: Bir dügüum noktasında akımı bilinmeyen dalın akım değeri Kirşof Akım Kanunu’yla hesaplanabilir.

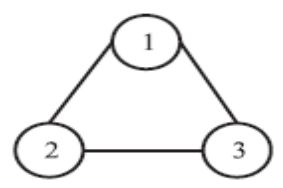

Şekil 1. Fazör ölçüm birimi yerleştirme kuralları

Belirtilen kurallar Şekil 1. üzerinden incelenirse;

Şekil 1'de 1. baraya FÖB yerleştirildiğinde Kural 1'e göre 1. baranın gerilimi, 1-2 ve 1-3 hatları arasındaki akımlar elde edilir. Kural 2'ye göre 2. ve 3. baranın gerilimi bilinir. Kural 3'e göre gerilim değeri bilinen 2 baranın hat akımı hesaplanabilir [21, 22].

\section{B. BENZETILMIŞ TAVLAMA ALGORİTMASI}

1980'lerde Kirkpatrick vd. kombinatoryal optimizasyon problemlerinin maliyet fonksiyonunu en aza indirgemek ile katının düşük enerjili temel duruma ulaşana kadar yavaş yavaş soğutulması arasında bir benzerlik olduğunu bularak yeni bir teknik geliştirmişlerdir. Bu tekniğe de benzetilmiş tavlama algoritması adını vermişlerdir. $\mathrm{Bu}$ algoritma metallerin tavlama işlemine benzediğinden bu adı 
almıştır. Diğer sezgisel algoritmalar gibi en iyi çözümü en kısa sürede elde etmeyi amaç edinir. Benzetilmiş tavlama algoritması uygulandıkları mühendislik çözümlerinde başarılı sonuçlar vermiştir [23].

Benzetilmiş tavlama algoritması, yerel arama algoritmalarının yerel minimuma ulaştıktan sonra algoritmayı sonlandırıp global minimumu aramamasından kaynaklanan eksikliği gidermek için önerilmiş bir algoritmadır. Benzetilmiş tavlama bir noktada diğer yerel arama algoritmalarından ayrılır. Bu fark yerel minimum veya maksimumu bulduktan sonra mevcut çözümden daha iyi bir global minimum ve maksimumu aramasıdır.

Benzetilmiş tavlama algoritmasının akış şeması Şekil 2'de gösterilmiştir.

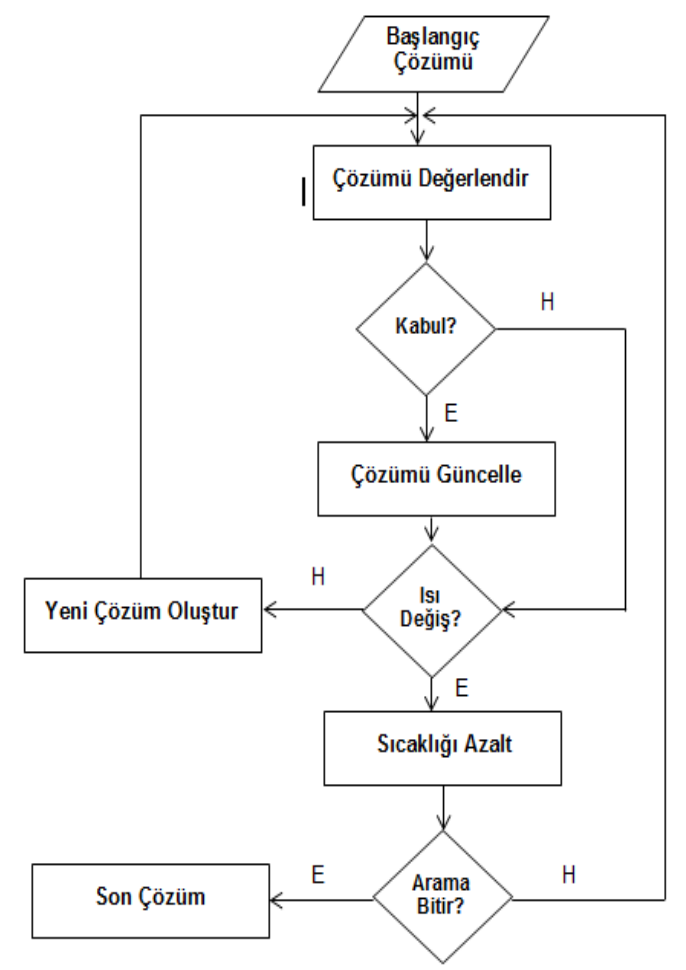

Şekil 2. Benzetilmiş tavlama algoritması akış şeması

Benzetilmiş tavlama algoritmaları bir başlangıç çözümünün seçilmesi ve amaç fonksiyonunun hesaplanması ile başlar. Yeni veya komşu bir çözüm rastgele oluşturulur ve amaç fonksiyonu tekrar hesaplanır. Amaç fonksiyonundaki değişim değerlendirilir. Bu prosedür durdurma kriterine gelinceye kadar devam eder.

Temel bir benzetilmiş tavlama algoritmasının adımları aşağıda verilmiştir [24].

Bir başlangıç çözümü oluştur, $s_{0}$.

Bir başlangıç sıcaklığı oluştur, $T_{0}$.

$T_{0}>0$

Rastgele bir komşu çözüm seç.

$s \in \mathrm{N}\left(s_{0}\right)$

Amaç fonksiyonun değerindeki farkı hesapla. 
Ĕger;

$\Delta>0 \rightarrow \mathrm{s}=s_{0}$

$s_{0}$ çözümü s'ten daha iyi ise yeni çözüm olarak ata. Aksi takdirde mevcut çözümü kullan. Sıcaklığı güncelle. Sonuçları değerlendir. Durdurma kriteri sağlanana dek işleme devam et. Kriter sağlandığında elde edilen sonucu son çözüm olarak kullan.

\section{B.1. Benzetilmiş Tavlama Algoritmasının Optimal FÖB Yerleşimine Uygulanması}

Benzetilmiş tavlama algoritmasının optimal FÖB yerleşimine uygulanması ilk olarak Baldwin vd. tarafından önerilmiş ve uygulanmıştır. Çalışmada minimum FÖB için hem modifiye edilmiş ikiye bölme metodu hem de benzetilmiş tavlama tabanlı bir yöntem kullanan ikili arama algoritması kullanılmıştır [25].

Bu yöntem sırasıyla sistemi gözlemlenebilir ve gözlemlenemez yapan FÖB'lerin sayısından oluşan üst ve alt limitlere sahip bir dizi arama aralı̆̆ını dikkate alır. Her aralıkta yeni bir üst veya alt limit olmaya aday olarak bir nokta seçilir. Başlangıç alt limit $\boldsymbol{\nu}_{l}$, ilk başlangıç değeri $\boldsymbol{\nu}_{\text {init }}$, başlangıç üst limiti $\boldsymbol{\nu}_{u}$ olarak tanımlanmıştır. Başlangıç alt sınırı " 0 " olarak belirlenmiştir. $\boldsymbol{\nu}_{\min }$ değerini bulmak için daha hızlı yöntem olarak $\boldsymbol{\nu}_{l}$ 'nin "0" olduğu aralık için orta noktayı seçmek yerine $0.85 \boldsymbol{\nu}_{u}$ değeri kullanılır.

Önerilen yöntem 6 adımdan oluşmakta ve 4. adımdan itibaren benzetilmiş tavlama algoritması süreci başlamaktadır. Önerilen yöntem bir E amaç fonksiyonun tanımlanıp minimize edilmesini, FÖB yerleşimi sağlayan rastgele üretici ve monoton olarak azalan $\mathrm{T}$ fonksiyonun tanımını gerektirir. Enerjiye benzer olan amaç fonksiyonu E, gözlenmeyen bara sayısı olan $\phi$ (S) fonksiyonu olarak seçilmiştir. Fonksiyon, $\boldsymbol{\nu}_{\text {test }}$ boyutundaki FÖB yerleştirme setlerinin arama alanı üzerinde minimize edilmiştir. Arama alanı, komşu setler arasından bir sonraki yerleştirme setini keyfi olarak seçen rastgele üreteç fonksiyonu kullanılarak sıralı olarak araştırılır. Bu sıra, kristal malzemelerin tavlama sürecindeki atomik hareketine benzer. Her bir yerleştirme seti, gözlemlenemeyen baraların sayısında bir azalma olup olmadığını belirlemek için önceki setle karşılaştırılır. Azalma varsa yeni yerleşim grubu eskisinin yerini alır. Aksi takdirde yeni yerleştirme seti soğutma sicaklığına benzer bir fonksiyon olan $\mathrm{T}$ tarafindan kontrol edilen olasılık fonksiyonuna göre eski setin yerini alacaktır.

Baldwin vd. yayınladıkları çalışmada benzetilmiş tavlama algoritmasını optimal FÖB yerleşimine uyarlayan bir kod parçacığı paylaşmışlardır. Kod Şekil 3 'te paylaşılmış ve açıklanmıştır. 


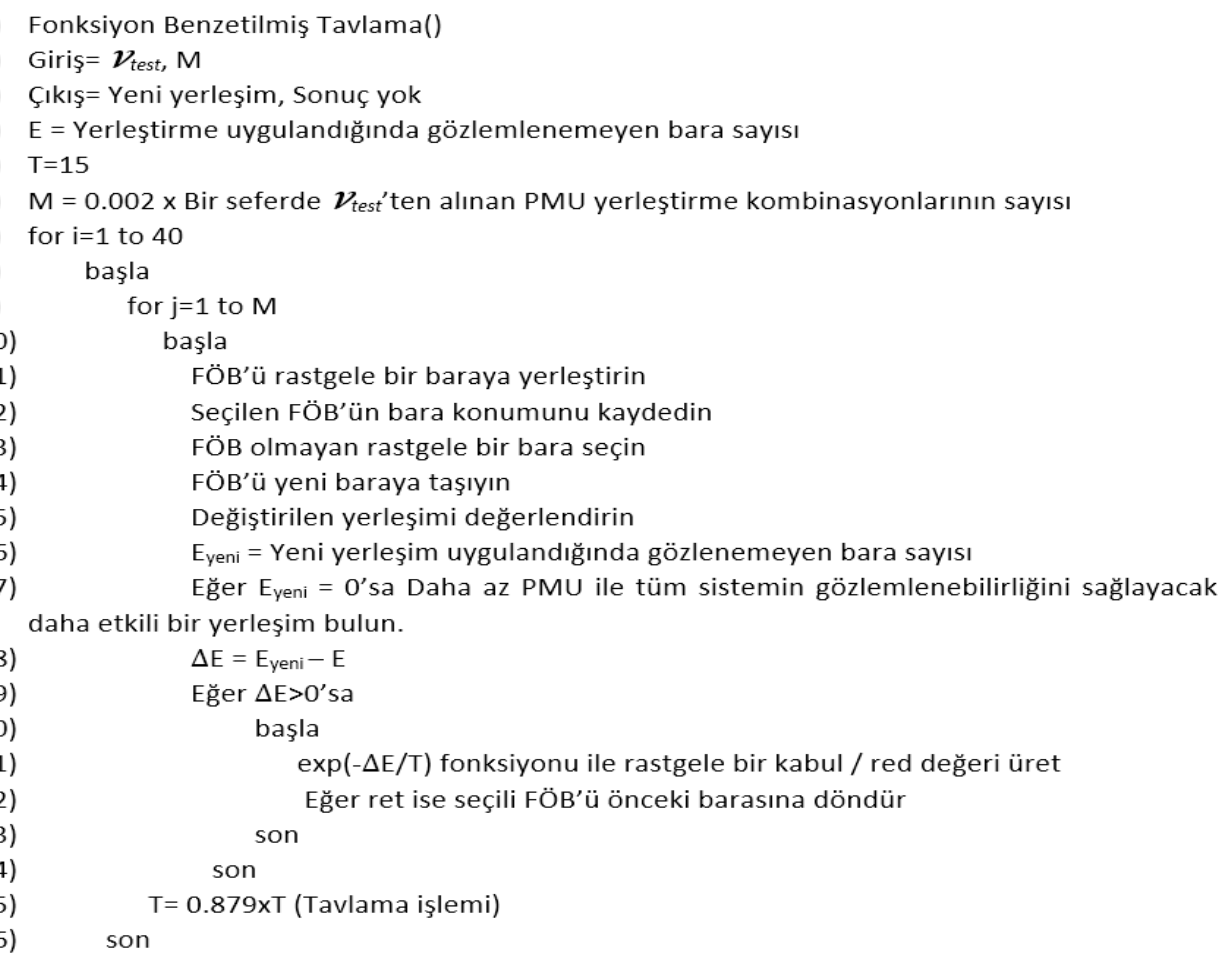

Şekil 3. Benzetilmiş tavlama algoritması için kullanılan kod parçacı̆̆ı

Algoritma grafik teorik prosedür tarafindan bulunan belirli FÖB yerleştirme setinden başlayarak, $\boldsymbol{\nu}_{\text {test }}$ FÖB yerleşimleri rastgele seçilir. Yeni yerleşim seçimi mevcut yerleştirme setinden rastgele bir FÖB seçilerek ve rastgele seçilen yeni bir baraya taşınarak bulunur. Daha sonra, hedef fonksiyon E yeni yerleştirme seti için yeniden değerlendirilir. Yeni FÖB yerleştirme setinin kabul edilip edilmeyeceğine ilişkin karar, $\Delta \mathrm{E}$ amaç fonksiyonunun artan değişikliğine ve T'nin değerine dayanmaktadır. $\Delta \mathrm{E}$ negatif olduğunda yeni yerleşim otomatik olarak kabul edilir. Aksi takdirde, T'nin kontrol sıcaklığı olduğu modifiye Boltzmann fonksiyonu tarafindan verilen olasılıkla kabul edilir. Belirli bir sicaklık değerlerinde birkaç adım denendikten sonra, sıcaklık $(\mathrm{T})$ düşürülür ve ardından yeni bir dizi adım denenir. Benzetilmiş tavlama algoritmasının herhangi bir uygulamasında, belirli bir sıcaklıktaki adım sayısının nasıl düzenleneceği, sıcaklığın nasıl azaltılacağı ve ne zaman durdurulacağının belirlenmelidir.

$$
P(\Delta \mathrm{E})=e^{(-\Delta \mathrm{E} / T)}
$$

Belirli bir sıcaklıkta değerlendirilen FÖB yerleştirme setlerinin sayısı M'dir ve arama alanının boyutuna bağlıdır. Arama alanında $\left(\begin{array}{c}N \\ v \text { test }\end{array}\right)$ kadar yerleşim seti vardır. Sayısal deneylerden M değerinin en uygun değerinin,

$M=0.002\left(\begin{array}{c}N \\ \text { vtest }\end{array}\right)$

olduğu belirlenmiştir.

Başlangıç sıcaklık değeri $T_{0}, \Delta \mathrm{E}$ 'nin büyüklüğüne bağlıdır. Bir FÖB bara değiştirdiğinde 5 ya da daha az bara gözlemlemesi beklenir. Bu değer şebekeye göre değişkenlik gösterir. $T_{0}$ değeri ortalama mutlak değişim değerinin yaklaşık üç katına ayarlanır. $\mathrm{Bu}$ da $T_{0}$ değerinin $15{ }^{\circ} \mathrm{C}$ olmasını sağlar. Başlangıç sıcaklığı, hedef fonksiyonun herhangi bir yerel minimumundan kaçmak ve FÖB yerleşimlerine geniş firsatlar sağlamak için $\Delta \mathrm{E}$ 'nin maksimum değerinden daha büyük olacak şekilde sezgisel olarak seçilir. Benzetilmiş tavlama algoritmalarının kullanıldığı standart uygulamada olduğu 
gibi kontrol sıcaklığı denkleme göre azaltılır.

$T_{i}=T_{0} \cdot \beta^{i}$

$T_{0}=$ Başlangıç sicaklığı

$\beta=$ Ölçekleme faktörü

$i=$ Algoritmadaki sıcaklık adımlarının yineleme sayacı

T parametresi 0,879 'luk bir ölçeklendirme faktörü kullanılarak 15 'ten 0,0869 değerine düşürülür. Algoritmadaki ölçeklendirme faktörü 40 olacak şekilde seçilmiştir.

Benzetilmiş tavlama algoritması üç durum ile karşılaşırsa sona erer. İlk durdurma kuralı, gözlenemeyen bara sayısı olarak seçilen $\mathrm{E}$ fonksiyonunun minimum değere ulaşmasıdır. Böyle bir durum için sistem zaten gözlenebilir olmaktadır. İkinci durdurma kuralı belirli bir kontrol sıcaklığı için kabul edilecek bir FÖB yerleşim setinin olmamasıdır. Bu tavlama işleminde 'donma noktası' anlamına gelmektedir. İşleme devam etmek için kontrol sıcaklığı yükseltilerek yeni bir yerleşim elde edilmeye çalışılmalıdır. Üçüncü kural ise izin verilen minimum kontrol sıcaklığı $T_{L}$ 'ye ulaşılmasıdır. $T_{L}, \Delta \mathrm{E}^{\prime}$ nin amaç fonksiyonundaki değişiklik olduğu durumda, amaç fonksiyonunun değerini artıran yeni bir yerleştirme setini kabul etme olasılı $\mathrm{g} 1 \mathrm{P}_{\text {acc }}$ ile ilgilidir [25, 26].

$T_{L}=\frac{-1}{\ln \left(P_{\text {acc }}\right)}$

\section{BULGULAR VE TARTISMA}

$\mathrm{Bu}$ çalışmada benzetilmiş tavlama algoritması ile FÖB'lerin optimal yerleşimi üzerine çalışılmıştır. Öncelikle kullanılan algoritmayı test etmek amaciyla IEEE'nin 14 ve 30 baralı sistemleri kullanılmıştır. Elde edilen sonuçlar, aynı sistem üzerinde farklı algoritmalardan elde edilen sonuçlarla karşılaştırılmış ve başarılı sonuçlar elde edildikten sonra algoritma, Trakya Güç Sistemi'ne uygulanmış ve sonuçlar PSAT'ın FÖB yerleştirme algoritmalarıyla karşılaştırılmıştır.

\section{A. IEEE TEST SISTEMLERE BENZETILMIŞ TAVLAMA ALGORITTMASI İLE OPTIMAL FÖB YERLEŞIMI}

IEEE'nin 14 ve 30 baralı sistemlerine optimal FÖB yerleşimi gerçekleştirilmiştir. Test edilen sistemlerin tek hat şemaları aşağıda verilmiştir. Benzetilmiş tavlama algoritması ve literatürdeki çalışmalarda elde edilen sonuçlar da aşağıdaki tablolarda verilmiştir. 


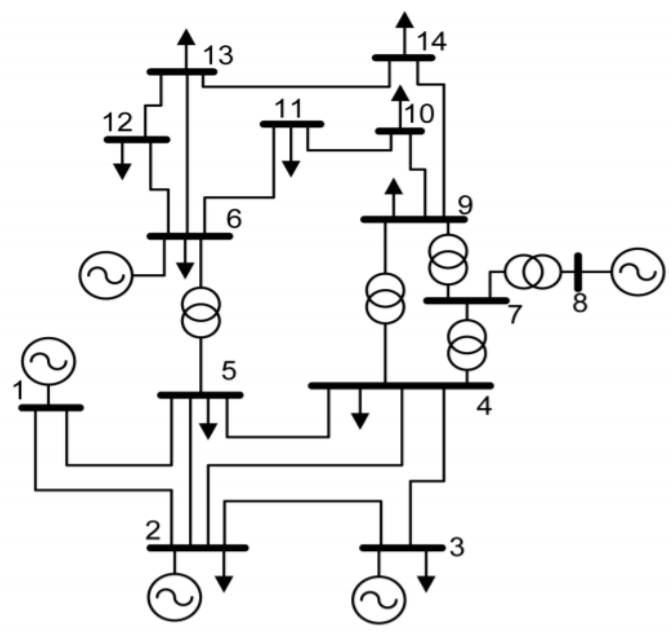

Şekil 4. IEEE 14 baralı sistemin tek hat şeması

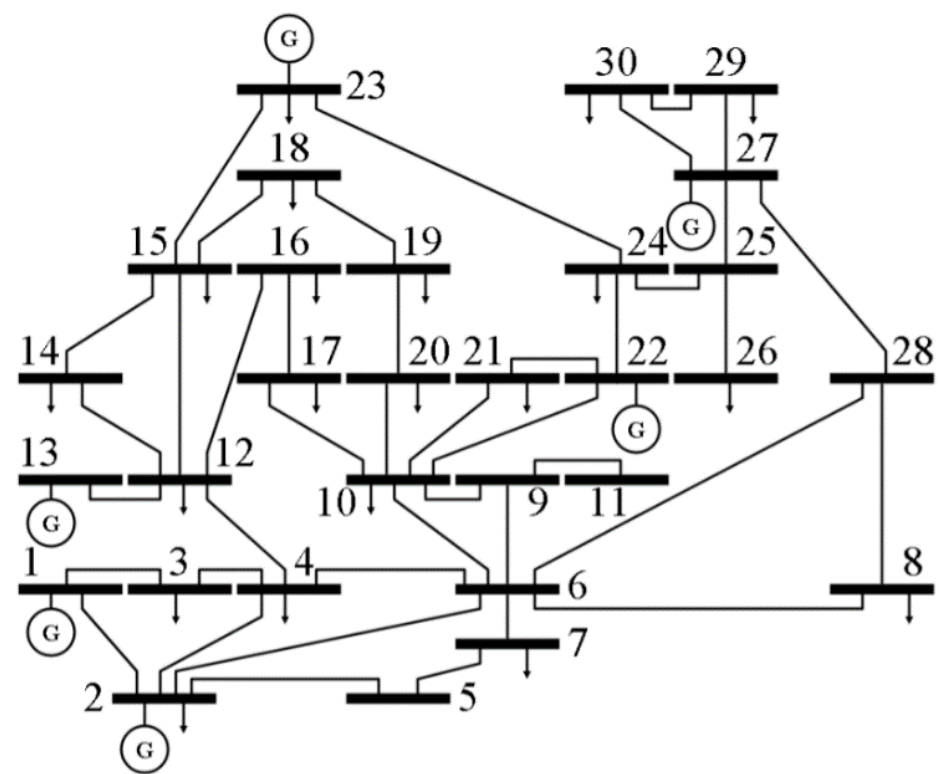

Şekil 5. IEEE 30 baralı sistemin tek hat şeması

Tablo 1. IEEE test sistemleri için gerekli FÖB sayıları

\begin{tabular}{ccc}
\hline Kullanılan Algoritma & \multicolumn{2}{c}{ Test Sistemleri } \\
\hline & 14 Bara & 30 Bara \\
\cline { 2 - 3 } Benzetilmiş Tavlama Algoritmas1 & 3 & 8 \\
\hline Diferansiyal Evrim Algoritması & 4 & 10 \\
\hline Genetik Algoritma & 4 & 10 \\
\hline Parçacık Sürü Optimizasyonu & 4 & 10 \\
\hline
\end{tabular}

IEEE 14 ve 30 baralı test sistemine yapılan optimal FÖB yerleştirme sonuçları için Tablo 1 incelendiğinde benzetilmiş tavlama algoritması, 14 baralı sistemde 3 ve 30 baralı sistemde 8 adet FÖB yerleştirerek sistemin tamamını gözlemlenebilir hale getirmektedir. Elde edilen sonuçları karşılaştırmak için literatürde incelenmiş diğer sezgisel algoritmaların sonuçları kullanılmıştır. 14 baralı sistem için sonuçlar incelendiğinde; diferansiyel evrim algoritması, genetik algoritma ve parçacık sürü optimizasyonunun 4 adet FÖB kullanarak sistemi gözlemlenebilir hale getirdiği görülmüştür. 30 baralı sistem için sonuçlar incelendiğinde ise; diferansiyel evrim algoritması, genetik 
algoritma ve parçacık sürü optimizasyonunun 10 adet FÖB kullanarak sistemi gözlemlenebilir hale getirdiği görülmüştür. Test sistemi için sonuçlar incelendiğinde en iyi sonuçları benzetilmiş tavlama algoritmasının verdiği görülmektedir [14], [27], [28].

Tablo 2. IEEE test sistemleri için FÖB 'lerin yerleştirilmesi gereken baralar

\begin{tabular}{|c|c|c|}
\hline \multirow[t]{2}{*}{ Kullanılan Algoritma } & \multicolumn{2}{|c|}{ Test Sistemleri } \\
\hline & 14 Bara & 30 Bara \\
\hline $\begin{array}{c}\text { Benzetilmiş Tavlama } \\
\text { Algoritması }\end{array}$ & $2,6,9$ & $1,5,6,10,12,18,24,27$ \\
\hline $\begin{array}{l}\text { Diferansiyel Evrim } \\
\text { Algoritmas1 }\end{array}$ & $2,6,7,9$ & $\begin{array}{c}1,5,6,9,10,12,18,24 \\
25,27\end{array}$ \\
\hline Genetik Algoritma & $2,6,7,9$ & $\begin{array}{c}2,4,6,9,10,12,15,19 \\
25,27\end{array}$ \\
\hline $\begin{array}{l}\text { Parçacık Sürü } \\
\text { Optimizasyonu }\end{array}$ & $2,6,7,9$ & $\begin{array}{c}1,5,6,9,10,12,15,19 \\
25,27\end{array}$ \\
\hline
\end{tabular}

\section{B. TRAKYA GÜÇ SISTEMINE OPTIMAL FÖB YERLEŞIMİ}

Trakya Güç Sistemi 154 ve 380 kV'luk 89 bara ve 161 iletim hattından oluşmaktadır [29]. Optimal FÖB yerleşimi için benzetilmiş tavlama algoritması kullanılmıştır. Elde edilen sonuçları karşılaştırmak için Trakya Güç Sistemi PSAT üzerinde Şekil 7'de gösterildiği gibi modellenmiştir. PSAT üzerinde graf teorisi, derinlik arama metodu ve minimum kapsayan ağaç metotları kullanılmıştır.

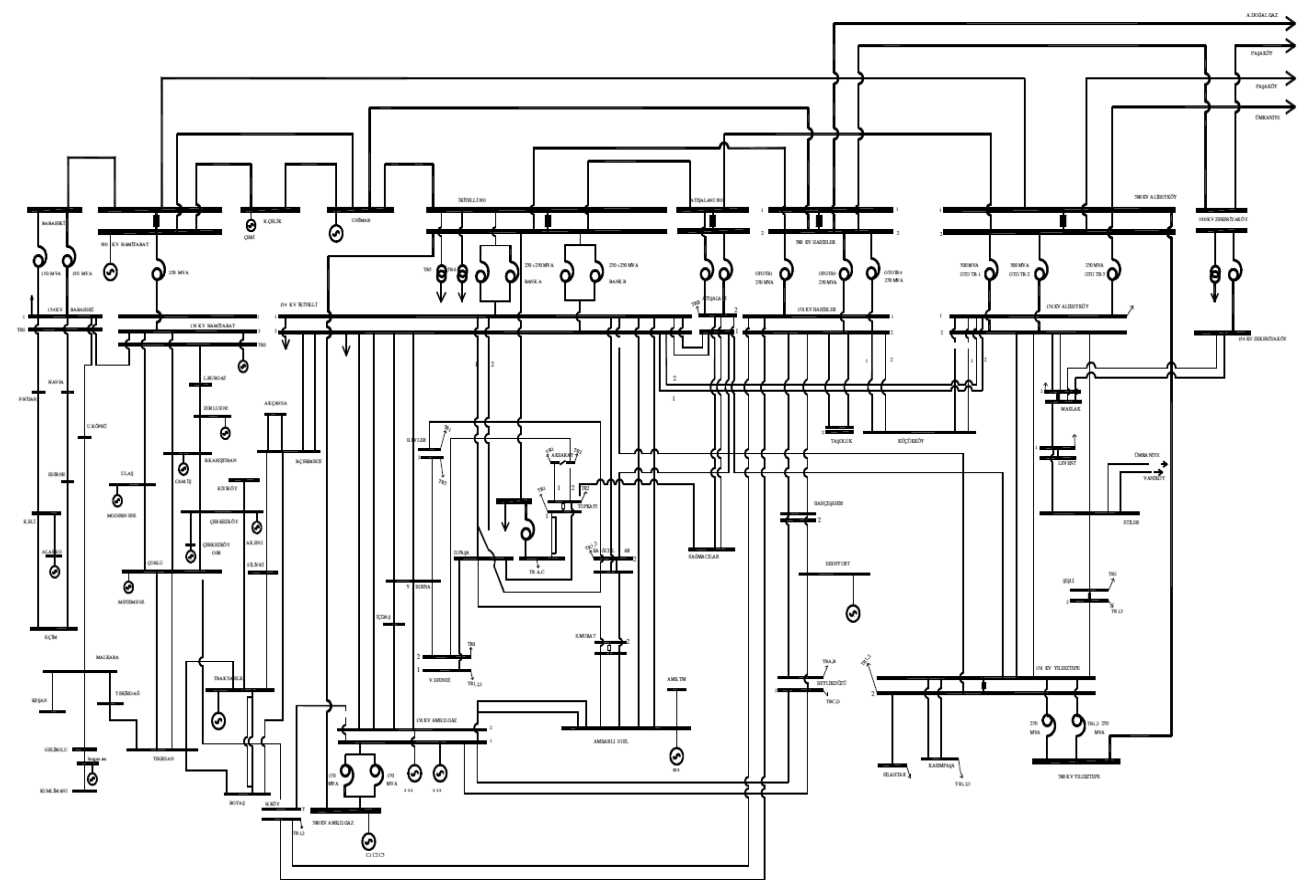

Şekil 6. Trakya güç sistemi 


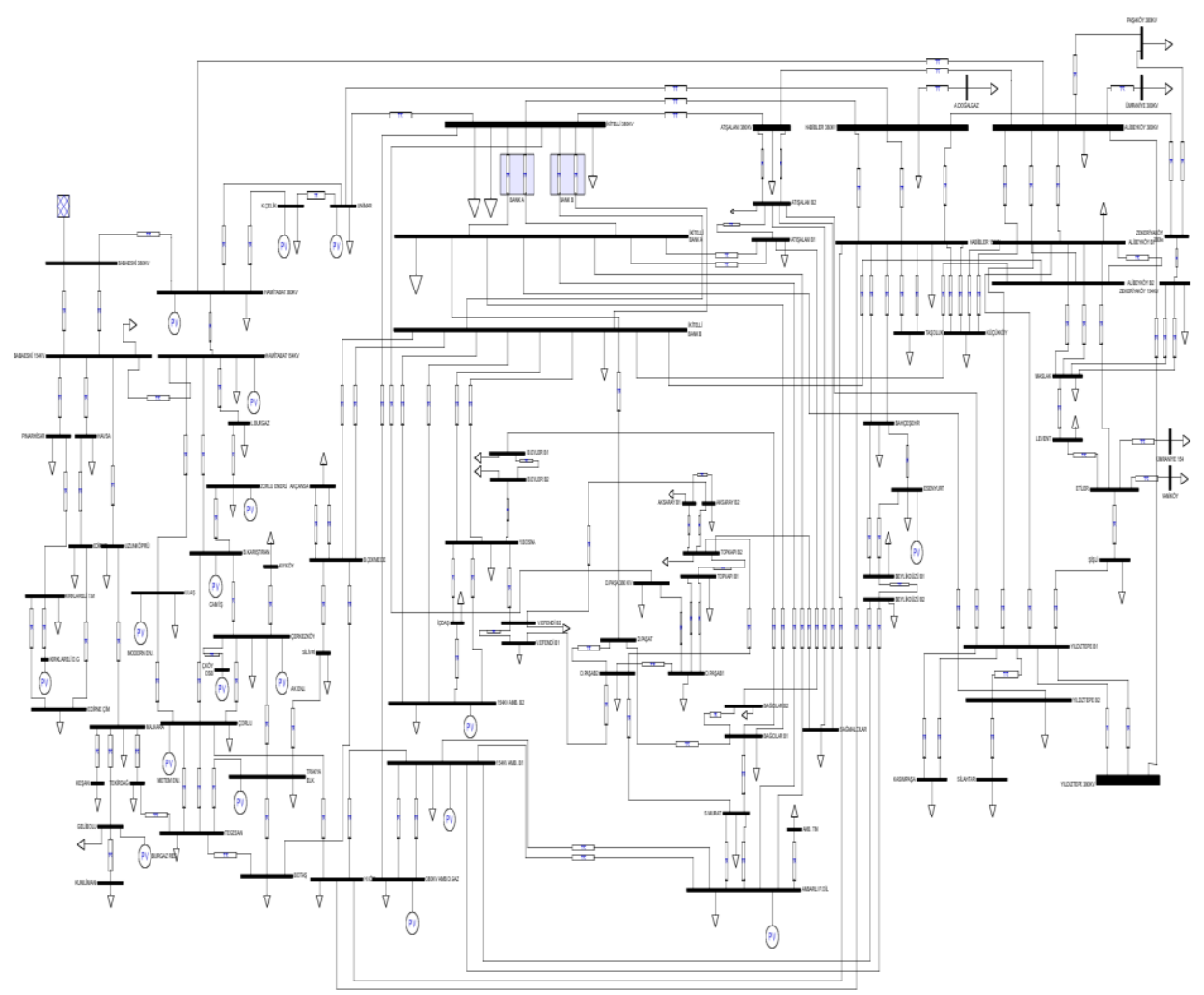

Şekil 7. Trakya güç sisteminin PSAT'ta modellenmesi

Optimal FÖB yerleşimi gerçekleştirildikten sonra elde edilen sonuçlar Tablo 3 ve Tablo 4'te verilmiştir.

Tablo 3. Trakya güç sistemi için gerekli FÖB sayıları

\begin{tabular}{cc}
\hline Kullanılan Algoritma & $\begin{array}{c}\text { Yerleştirilmesi Gereken FÖB } \\
\text { sayısı }\end{array}$ \\
\hline Benzetilmiş Tavlama Algoritması & 34 \\
\hline Derin Öncelikli Arama Metodu & 37 \\
\hline Graf Teorisi Metodu & 36 \\
\hline Minimum Kapsayan Ağaç Algoritması & 42 \\
\hline
\end{tabular}

Tablo 3'te sistemin tamamını gözlenebilir hale getirmek için yerleştirilmesi gereken FÖB sayıları verilmiştir. Benzetilmiş tavlama algoritması ile 34 adet FÖB kullanılarak Trakya Güç Sistemi'nin tamamı gözlenebilir hale gelmektedir. Karşılaştırma yapmak için PSAT FÖB yerleştirme algoritmaları kullanıldığında; derin öncelikli arama metodu 37, graf teorisi metodu 36, minimum kapsayan ağaç algoritması ise 42 adet FÖB yerleştirerek sistemin tamamını gözlenebilir hale getirmektedir. En iyi sonucu benzetilmiş tavlama metodu vermektedir.

Trakya Güç Sistemi için FÖB'lerin yerleştirilmesi gereken baralar numaralandırılarak Tablo 4'te gösterilmiştir. 
Tablo 4. Trakya güç sistemi için FÖB'lerin yerleştirilmesi gereken baralar

\begin{tabular}{|c|c|}
\hline Kullanılan Algoritma & FÖB'lerin Yerleştirilmesi Gereken Baralar \\
\hline $\begin{array}{c}\text { Benzetilmiş Tavlama } \\
\text { Algoritması }\end{array}$ & $\begin{array}{c}2,3,8,11,14,15,17,18,19,20,22,23,25,29,32,35, \\
38,41,44,46,49,53,56,57,61,63,65,67,71,79,81, \\
83,86,88\end{array}$ \\
\hline $\begin{array}{c}\text { Derin Öncelikli Arama } \\
\text { Metodu }\end{array}$ & $\begin{array}{c}2,3,11,14,15,16,17,18,19,20,22,23,25,29,32,35 \\
38,41,45,47,49,50,54,60,62,68,72,73,74,79,82 \\
84,85,86,87,88,89\end{array}$ \\
\hline Graf Teorisi Metodu & $\begin{array}{c}2,3,11,14,15,16,17,18,19,20,22,23,25,29,32,35 \\
38,41,45,47,49,50,54,60,62,68,72,73,74,79,84 \\
85,86,87,88,89\end{array}$ \\
\hline $\begin{array}{l}\text { Minimum Kapsayan } \\
\text { Ağaç Algoritması }\end{array}$ & $\begin{array}{c}2,3,4,6,8,9,11,16,17,18,20,24,26,29,32,35,38 \\
40,41,42,43,44,46,49,53,55,56,57,59,61,62,63 \\
64,67,70,71,73,76,79,80,81,83\end{array}$ \\
\hline
\end{tabular}

\section{SONUC VE ÖNERILER}

FÖB'ler güç sistemlerinin durumu anlık olarak değerlendirmek için önem arz etmektedir. Güç sistemlerinde maliyet kısıtı nedeniyle tüm baralara FÖB birimi yerleştirilmesi mümkün olmamaktadır. $\mathrm{Bu}$ da optimizasyon problemini ortaya çıkarmaktadır. Bu çalışmada optimal yerleşim için benzetilmiş tavlama algoritması seçilmiş, IEEE test sistemlerinde test edilerek Trakya Güç Sistemine uygulanmıştır. Sonuçlar incelendiğinde benzetilmiş tavlama algoritması diğer algoritmalara göre en az sayıda FÖB kullanarak tam gözlenebilirlik sağlamıştır. Maliyet kısıtı düşünüldüğünde en az sayıda FÖB ile tam gözlenebilirlik sağlamak büyük önem taşımaktadır. İlerleyen çalışmalarda sistem için önem arz eden kritik baralara FÖB yerleştirildiğinde ortaya çıkacak olan optimal yerleşim durumları incelenebilir.

\section{KAYNAKLAR}

[1] A. G. Phadke, "Synchronized Phasor Measurements in Power Systems," IEEE Computer Applications in Power, vol. 6, no. 2, pp. 10-15, 1993.

[2] A. G. Phadke, "System of Choice," IEEE Power and Energy Magazine, vol. 6, no. 5, pp. 20$22,2008$.

[3] N. M. Manousakis, G. N. Korres and P. S. Georgilakis, "Taxonomy of PMU Placement Methodologies," IEEE Transactions on Power Systems, vol. 27, no. 2, pp. 1070-1077, 2012.

[4] A. G. Phadke ve J. S. Thorp, "History And Applications of Phasor Measurements," IEEE PES Power Systems Conference and Exposition, Atlanta, Amerika, pp. 331-335, 2006.

[5] K. Mazlumi ve H. Vahedi, "Optimal Placement of PMUs in Power Systems Based On Bacterial Foraging Algorithm," 18th Iranian Conference on Electrical Engineering, Isfahan, İran, pp. 885-888, 2010.

[6] K. E. Martin vd., "IEEE Standard for Synchrophasors for Power Systems," IEEE Transactions 
on Power Delivery, vol. 13, no. 1, pp. 73-77, 1998.

[7] D. Chouhan and V.Jaiswal, "A Literature Review on Optimal Placement of PMU and Voltage Stability." Indian Journal of Science and Technology, vol. 9, pp. 1-7, 2016.

[8] K.P. Lien, C.W. Liu, C.S. Yu ve J.A. Jiang, "Transmission Network Fault Location Observability with Minimal PMU Placement," IEEE Transactions on Power Delivery, vol. 21, no. 3, pp. 1128-1136, 2006.

[9] S. Chakrabarti ve E. Kyriakides, "Optimal Placement of Phasor Measurement Units for Power System Observability," IEEE Transactions on Power Systems, vol. 23, no. 3, pp. 1433-1440, 2008.

[10] R.Sodhi, S.C. Srivastava, S.N. Singh, "Optimal PMU Placement Method for Complete Topological and Numerical Observability of Power System," Electric Power Systems Research, vol. 80, pp. 1154-1159, 2010.

[11] S. Chakrabarti, E. Kyriakides ve D. G. Eliades, "Placement of Synchronized Measurements for Power System Observability," IEEE Transactions on Power Delivery, vol. 24, no. 1, pp. 12-19, 2009.

[12] F. J. Martin, F. Garcia-Lagos, G. Joya, F. Sandoval, "Genetic Algorithms for Optimal Placement of Phasor Measurement Units in Electrical Networks", IEEE Electronic Letters, vol. 39, 2003.

[13] M. Hajian, A. M. Ranjbar, T. Amraee ve A. R. Shirani, "Optimal Placement of Phasor Measurement Units: Particle Swarm Optimization Approach," 2007 International Conference on Intelligent Systems Applications to Power Systems, Toki Messe, Niigata, Japonya, pp. 1-6, 2007.

[14] A. H. Al-Mohammed, M. A. Abido ve M. M. Mansour, "Optimal PMU Placement For Power System Observability Using Differential Evolution," 2011 11th International Conference on Intelligent Systems Design and Applications, Cordoba, İspanya, pp. 277-282, 2011.

[15] C. Peng, H. Sun, J. Guo, "Multi-Objective Optimal PMU Placement Using A Non-Dominated Sorting Differential Evolution Algorithm," International Journal of Electrical Power \& Energy Systems, vol. 32, no. 8, pp. 886-892, 2010.

[16] H. A. Abdelsalam, A. Y. Abdelaziz and V. Mukherjee, "Optimal PMU Placement in a Distribution Network Considering Network Reconfiguration," 2014 International Conference on Circuits, Power and Computing Technologies, Nagercoil, Hindistan, pp. 191-196, 2014.

[17] S. Mandava, "A Spanning Tree Approach in Placing Multi-channel and Minimum Channel PMU's for Power System Observability," International Journal of Electrical and Computer Engineering c. 5, s. 3, ss. 518 524, 2015.

[18] A. Almunif, L. Fan, "Optimal PMU Placement for Modeling Power Grid Observability with Mathematical Programming Methods,” Int Trans Electr Energ Syst., ss. 1-13 2020.

[19] T. Johnson, T. Moger, "A Critical Review of Methods for Optimal Placement of Phasor Measurement Units," Int Trans Electr Energ Syst., ss. 1-25, 2020.

[20] P. Chunhua ve X. Xuesong, "A Hybrid Algorithm Based on Immune BPSO and N-1 Principle for PMU Multi-Objective Optimization Placement," Third International Conference on Electric Utility Deregulation and Restructuring and Power Technologies, Nanjing, Çin, ss. 610-614, 2008.

[21] N. H. A. Rahman ve A. F. Zobaa, "Optimal PMU Placement Using Topology Transformation 
Method in Power Systems,” J. Adv. Res., vol. 7, no 5, pp. 625-634, 2016.

[22] M.A.M. İpek, "Elektrik güç sistemlerinde geniş alan ölçüm sistemi ve fazör ölçüm birimi yerleşiminin incelemesi”, Yüksek Lisans Tezi, Fen Bilimleri Enstitüsü, İstanbul Teknik Üniversitesi, İstanbul, Türkiye, 2008.

[23] A. S. Kirkpatrick, C. D. Gelatt, M. P. Vecchi, "Optimization by Simulated Annealing," American Association for the Advancement of Science Stable, vol. 220, no 4598, pp. 671-680, 1983.

[24] A. Yılmaz, "Sonlu eleman modeli güncellemesi tekniğinde benzetilmiş tavlama algoritması kullanılarak mekanik sistemlerde hasar tespiti” Yüksek Lisans Tezi, Fen Bilimleri Enstitüsü, İstanbul Teknik Üniversitesi, İstanbul, Türkiye, 2008.

[25] T. L. Baldwin, L. Mili, M. B. Boisen ve R. Adapa, "Power System Observability with Minimal Phasor Measurement Placement," IEEE Transactions on Power Systems, vol. 8, no. 2, pp 707-715, 1993.

[26] P. Xu ve B. F. Wollenberg, "Power System Observability and Optimal Phasor Measurement Unit Placement," University of Minnesota, 2015.

[27] P. P. Bedekar, S. R. Bhide ve V. S. Kale, "Optimum PMU Placement Considering One Line/ One PMU Outage and Maximum Redundancy Using Genetic Algorithm," The 8th Electrical Engineering/ Electronics, Computer, Telecommunications and Information Technology (ECTI), Khon Kaen, Tayland, pp. 688-691, 2011.

[28] S. Chakrabarti, G. K. Venayagamoorthy ve E. Kyriakides, "PMU Placement for Power System Observability Using Binary Particle Swarm Optimization," Australasian Universities Power Engineering Conference, Sidney, Avustralya, pp. 1-5, 2008.

[29] O. Uslu, "Türkiye elektrik iletim şebekesinin trakya bölümünün kontrollü çalışma bölgelerine ayrılmasının incelenmesi," Yüksek Lisans Tezi, İstanbul Teknik Üniversitesi Fen Bilimleri Enstitüsü, İstanbul Teknik Üniversitesi, İstanbul, Türkiye, 2008. 